\title{
Functional outcomes of full-endoscopic spine surgery for high-grade migrated lumbar disc herniation: a prospective registry-based cohort study with more than 5 years of follow-up
}

\author{
Christopher Wu', Ching-Yu Lee ${ }^{2,3}$, Sheng Chi Chen ${ }^{4}$, Shao-Keh Hsu ${ }^{4 *+}$ and Meng-Huang $\mathrm{Wu}^{2,3^{*+}}$ (i)
}

\begin{abstract}
Background: Full-endoscopic lumbar discectomy (FELD) is an alternative to posterior open surgery to treat a highgrade migrated herniated disc. However, because of the complexity of the surgery, success is dependent on the surgeon's skill. Therefore, patients are frequently treated using open discectomy. Anatomical constraints and technical difficulties can lead to the incomplete removal of high-grade migrated discs.

Methods: We retrospectively reviewed patients who had undergone FELD performed by a single surgeon between January 2010 and January 2014 from a prospective spine registry in an institute. Perioperative records and data of the Oswestry Disability Index, visual analog scale scores (preoperatively and 2 weeks, 6 weeks, 3 months, 6 months, 1 year, 2 years, and 5 years after the operation), and MacNab criteria were collected.

Results: Of 58 patients with a follow-up duration of $>5$ years, (41 and 17 patients had undergone transforaminal endoscopic lumbar discectomy [TELD] and interlaminar endoscopic lumbar discectomy [IELD], respectively), the satisfaction rate was $87.8 \%$ (five unsatisfactory cases) for TELD and 100\% for IELD. The overall percentage of patients with good to excellent results according to modified MacNab criteria was 91.3\% (53/58 patients). Two patients had residual discs. Two patients needed an open discectomy due to recurrent disc herniation. One IELD patient received spinal fusion surgery due to segmental instability after 5 years.

Conclusion: FELD has a high success rate for the management of high-grade migrated herniated discs. In patients with high-grade disc migration from L1 to L5, TELD is effective and safe. However, for L4-L5 and L5-S1 high-grade upward and downward disc migration, IELD is the favorable option and provides high patient satisfaction.
\end{abstract}

Keywords: Discectomy, Full-endoscopic lumbar discectomy, Migrated disc herniation

\footnotetext{
* Correspondence: Skhsu823@gmail.com; maxwutmu@gmail.com

'Shao-Keh Hsu and Meng-Huang Wu contributed equally to this work.

${ }^{4}$ Department of Orthopedics, Tungs' Taichung MetroHarbor Hospital, No.699,

Sec. 8, Taiwan Blvd., Taichung City 435, Taiwan

2Department of Orthopaedics, School of Medicine, College of Medicine,

Taipei Medical University, Taipei, Taiwan

Full list of author information is available at the end of the article
}

(c) The Author(s). 2021 Open Access This article is licensed under a Creative Commons Attribution 4.0 International License, which permits use, sharing, adaptation, distribution and reproduction in any medium or format, as long as you give appropriate credit to the original author(s) and the source, provide a link to the Creative Commons licence, and indicate if changes were made. The images or other third party material in this article are included in the article's Creative Commons licence, unless indicated otherwise in a credit line to the material. If material is not included in the article's Creative Commons licence and your intended use is not permitted by statutory regulation or exceeds the permitted use, you will need to obtain permission directly from the copyright holder. To view a copy of this licence, visit http://creativecommons.org/licenses/by/4.0/. The Creative Commons Public Domain Dedication waiver (http://creativecommons.org/publicdomain/zero/1.0/) applies to the data made available in this article, unless otherwise stated in a credit line to the data. 


\section{Background}

In 1975, Hijikata described the first percutaneous discectomy; since then, full-endoscopic lumbar discectomy (FELD) has been frequently used for managing lumbar disc herniation [1, 2]. This alternative to conventional open discectomy has many benefits, such as decreased tissue trauma; lower postoperative instability; no interference with the epidural venous system, which, if damaged, may result in fibrosis and chronic neural edema; and faster recovery $[3,4]$.

Although FELD has many advantages, the indication for its use is mostly observed in patients with nonmigrated or low-grade migrated disc herniation. The incidence of migrated discs is approximately $35-72 \%$, and most patients have a downward low-grade migrated disc $(30.9 \%)$ [5, 6]. However, high-grade migrated discs are commonly observed (an incidence of 34\% for migrated discs) $[6,7]$. Because of the high failure rate of FELD in high-grade migrated disc herniation, open surgery is usually suggested; moreover, FELD is usually difficult because of anatomical barriers encountered when removing high-grade migrated discs, which can result in the incomplete removal of the disc material $[4,8]$.

Recently, the development of instruments and techniques has enabled the use of FELD to correct highgrade migrated lumbar discs. Many spine surgeons have developed novel techniques for managing high-grade migrated lumbar disc herniation by using FELD, including expanding the entry point of the transforaminal endoscopic lumbar discectomy (TELD) approach by using the foraminoplastic technique [4, 9-11], the transfacet process and pedicle-complex approach [12], two-level TELD [8], contralateral TELD [13], the suprapedicular approach [14], and the transpedicular approach [15, 16]. Alternatively, surgeons may opt to use a technique involving the posterior route, including the translaminar approach [17, 18], the interlaminar endoscopic lumbar discectomy (IELD) approach $[19,20]$, or adjacent IELD [21], which are similar to open surgery. Although improvements in equipment and techniques have resulted in better outcomes in FELD than in conventional open surgery, the management of high-grade migrated discs remains a challenge. In this study, we examined the long-term outcomes of patients with high-grade migrated disc herniation treated using FELD, and we reviewed the literature for the analysis of relevant surgical techniques.

\section{Methods \\ Patients and evaluation}

We retrospectively reviewed patients who had received FELD by a single surgeon between January 2010 and January 2014 from a prospective spine registry in an institute. Data concerning patients' age, sex, and treatment time as well as follow-up data were collected. The computed tomography $(\mathrm{CT})$ and magnetic resonance imaging (MRI) scans of patients were used to determine the level and extent of pathology. An intraoperative fluoroscopy examination was performed to ensure the correct positioning of the endoscope. The successful removal of migrated discs was determined using intraoperative findings (dural pulsation, loose neural element, retrieved disc fragments, and intraoperative symptoms) and postoperative symptoms. Herniated discs were classified using the radiological classification of migrated disc herniations provided by Lee et al. [22] (Table 1, Fig. 1). Migration into zone 1 and zone 4 was considered high-grade migration.

\section{Exclusion criteria}

Patients were excluded if they had spinal stenosis confirmed through CT or MRI; exhibited segmental instability; exhibited other pathological conditions, such as acute inflammation, infection, fractures, or tumors; or were lost to follow-up within 5 years. This study was approved by our institutional review board (TMU-JIRB No.: N201903139).

\section{Surgical technique \\ Surgical position}

During surgery, each patient was placed in a prone position to allow hip flexion to increase the available working space. This position reduces lordosis, allowing easy access to the spine.

\section{TELD}

For high migration at the L1-L2 to L4-L5 level, the transforaminal epiduroscopic approach was selected (Figs. 2, 3, and 4). Patients were locally anesthetized using $1 \%$ lidocaine. Before starting the surgery, the

Table 1 Radiological Classification of Migrated Disc Herniation [22]

\begin{tabular}{lll}
\hline Zone & Direction & Range of Distance \\
\hline Zone 1 & Far upward & From the inferior margin of the upper pedicle to $3 \mathrm{~mm}$ below the inferior margin of the upper pedicle \\
Zone 2 & Near upward & From $3 \mathrm{~mm}$ below the inferior margin of the upper pedicle to the inferior margin of the upper vertebral body \\
Zone 3 & Near downward & From the superior margin of the lower vertebral body to the center of the lower pedicle \\
Zone 4 & Far downward & From the center to the inferior margin of the lower pedicle \\
\hline
\end{tabular}



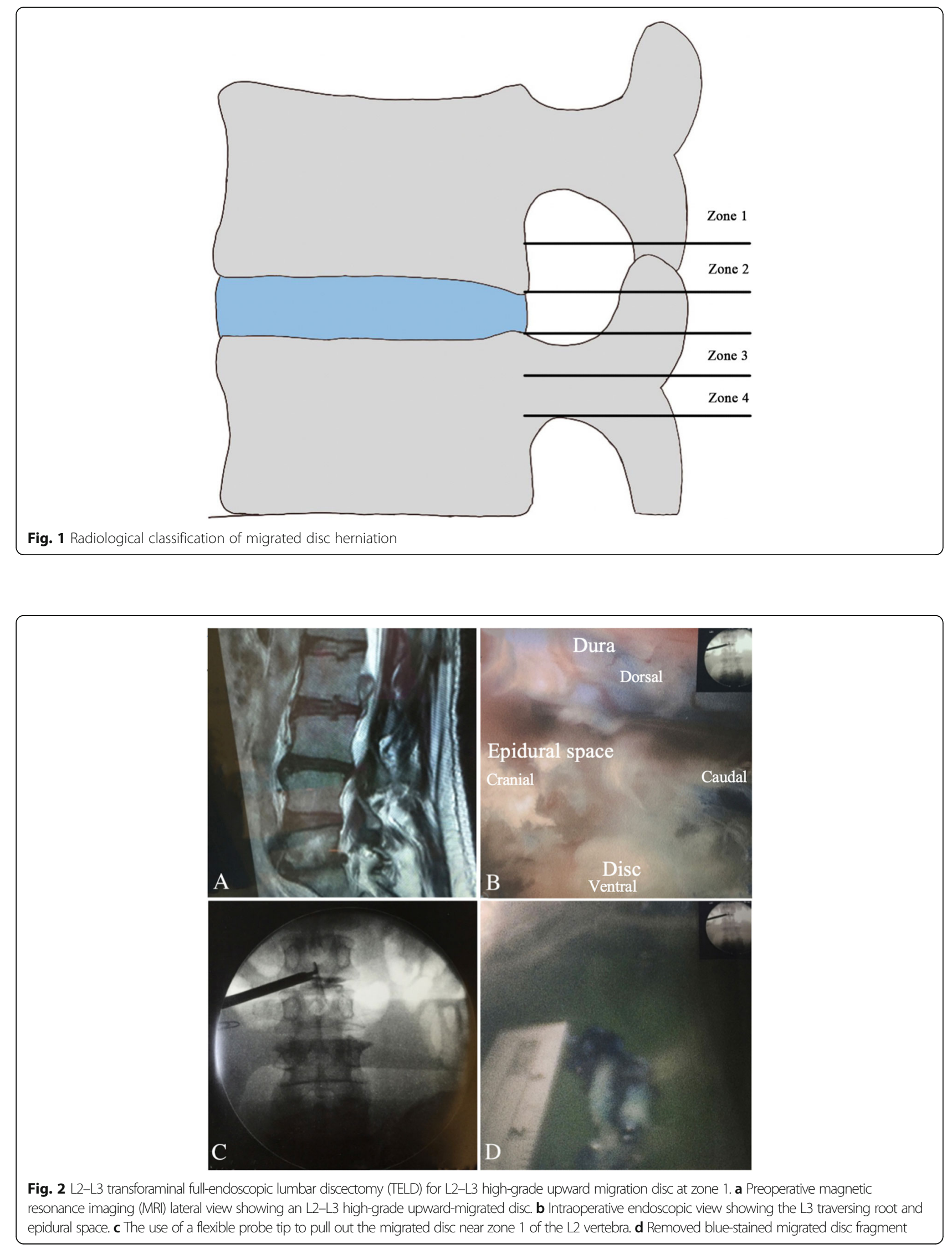

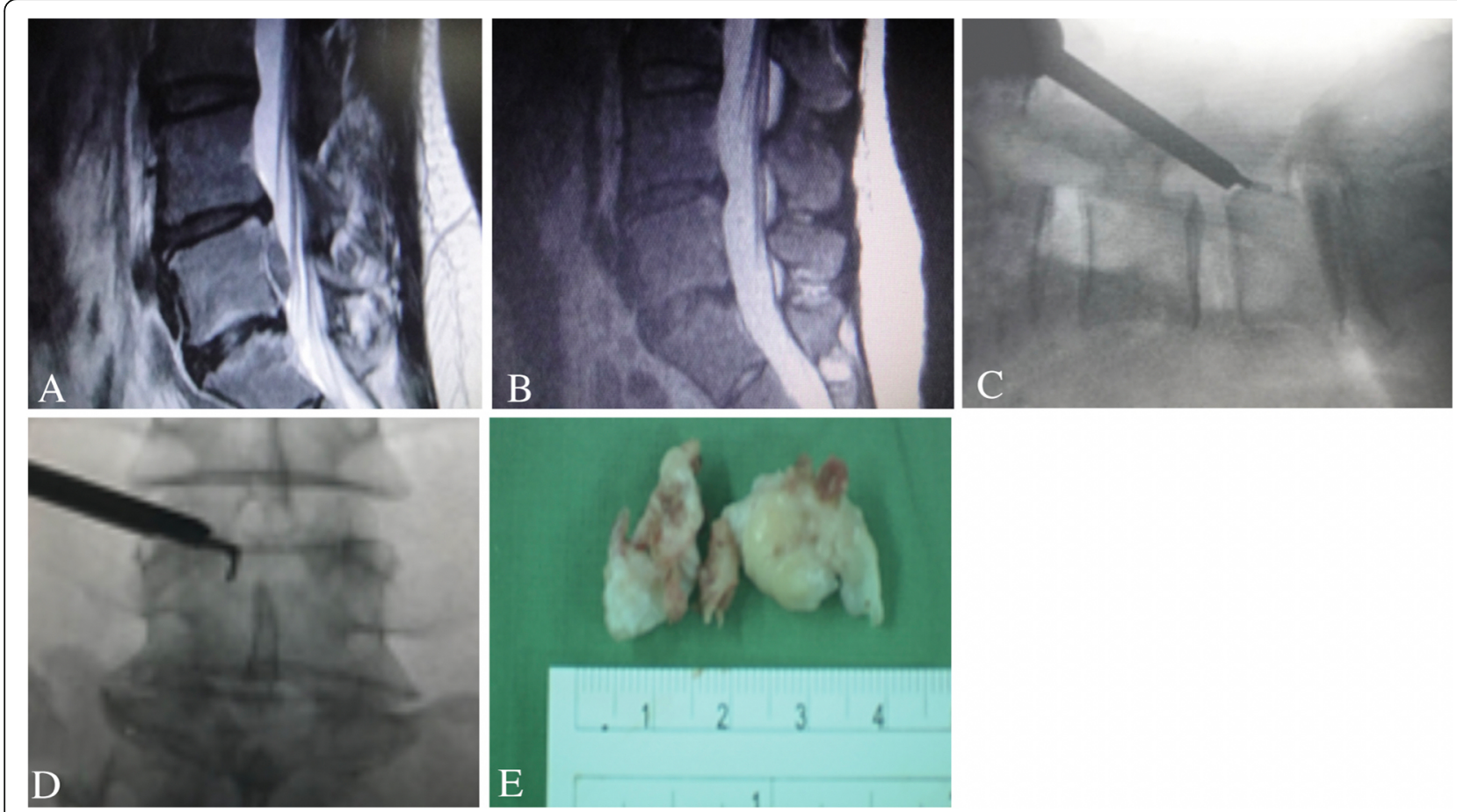

Fig. 3 TELD for L4-L5 high-grade downward migrated herniated disc at zone 4. a Preoperative MRI lateral view showing an L4-L5 downward migrated disc. $\mathbf{b}$ Postoperative MRI lateral view showing complete decompression after the removal of the migrated disc. c and $\mathbf{d}$ Intraoperative fluoroscopy view showing flexible dissecting forceps probing down-migrated disc fragments at zone 4. e Removed disc fragments

patient was placed in a prone position. To establish the entry site, preoperative imaging studies along with intraoperative fluoroscopy were conducted. The skin entry depended on the patient and was generally $8-15 \mathrm{~cm}$ lateral from the midline. The approach angle for the disc depended on the direction and zone of the disc location. If the disc exhibited upward migration, then a caudal to cranial approach angle was selected, whereas if the disc exhibited caudal migration, then a cranial to caudal approach was adopted. Methylene blue dye was injected into the disc space to visualize the leakage pattern in the annular fissure. Dilatation was subsequently performed, and endoscopic exploration was initiated. Intradiscal subannular debulking was performed until the border of

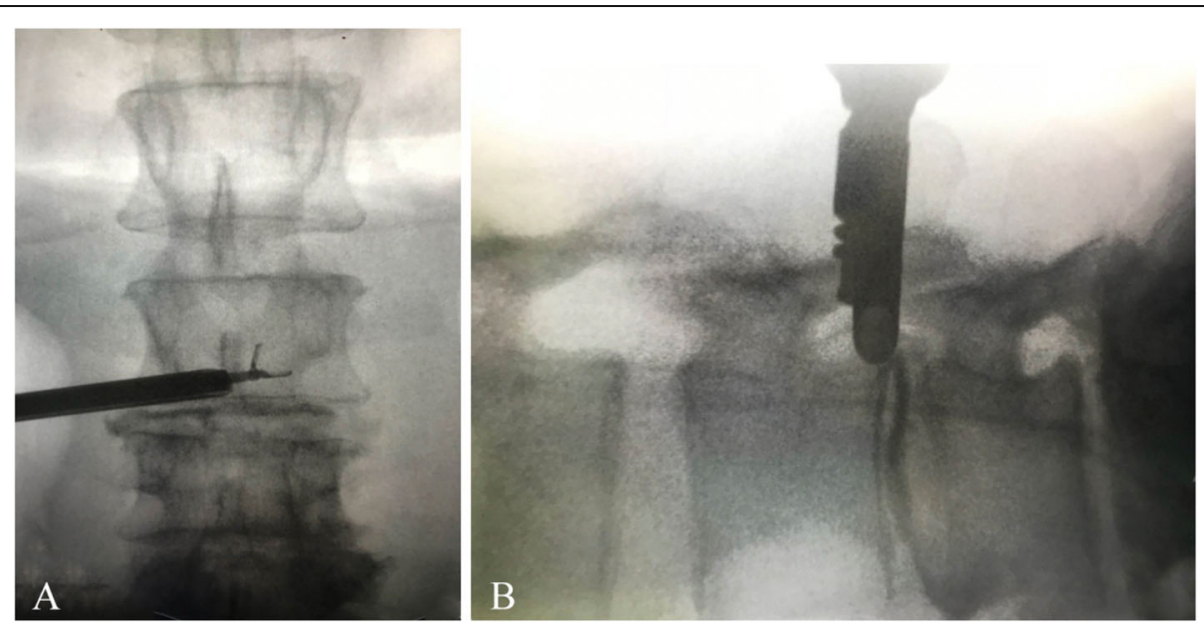

Fig. 4 Contralateral TELD for upperward migration of $L 3-L 4$ HIVD at zone 1. a Anterior to posterior view of intraoperative fluoroscopy showing the endoscopic micro rongeur forceps grasping the disc fragment at contralateral zone 1. b Lateral view of the intraoperative fluoroscopy working channel position located at the epidural space 
the annular fissure was uncovered. The outer layer of the annulus and the posterior longitudinal ligament were cut using a pair of annulus scissors. Once the outer annulus and posterior longitudinal ligament were cut, the epidural layer was released after the confirmation of the epidural space and the fragment of the migrated disc. This ventral decompression was expected to create additional working space to approach the disc that had migrated in the cranial or caudal direction. The herniated disc was observed after completing the epidural and intradiscal release. A pair of flexible forceps was used to remove the tip of the migrated disc under endoscopic and fluoroscopic guidance. The disc could be removed in one piece or in multiple pieces. Next, complete herniotomy was conducted by removing the entire herniation along with the intradiscal fragment, periannular
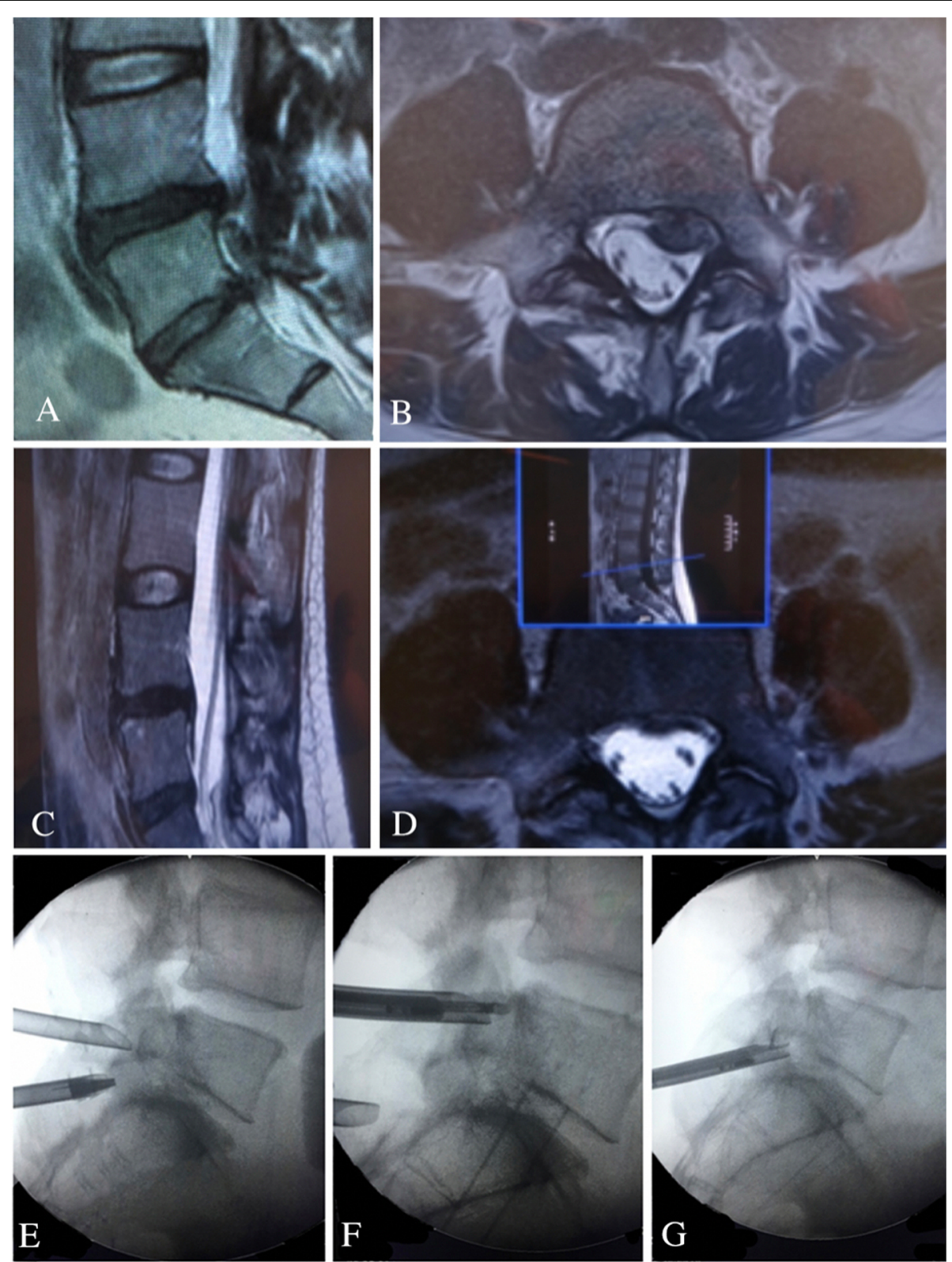

Fig. $5 L 4-L 5$ and $L 5-S 1$ interlaminar full-endoscopic lumbar discectomy (IELD) for L4-L5 high-grade downward migrated disc at zone 4 due to difficulty reaching the migrated fragment from L4-L5 IELD. a Preoperative MRI lateral view showing L4-L5 high-grade downward migration. $\mathbf{b}$ Preoperative MRI axial view showing L4-L5 herniated disc. c Postoperative MRI lateral view showing removal of the migrated disc. $\mathbf{d}$ Postoperative MRI axial view showing the removal of the migrated disc. e Intraoperative fluoroscopic view of the two working channels of the double IELD approach. $\mathbf{f}$ Intraoperative fluoroscopic view showing IELD from the L4-L5 interlaminar window for L4-S1 zone 4. g Intraoperative fluoroscopic view showing IELD for L5-S1 zone 1 
fragment, and fragment that had migrated from the site. For two L3-L4 upward-migrated discs, contralateral TELD was used.

\section{IELD}

IELD was performed in patients with L4-L5 high-grade downward disc migration or L5-S1 disc migration (Figs. 5, 6, and 7). The surgery was performed under general anesthesia. Patients were placed in the prone position, with their hips flexed to increase the interlaminar space. Soft tissue expanders were used to separate muscles to facilitate the insertion of the cannula and endoscope. The inferior edge of the cranial lamina on the side of the lesion and the ligamentum flavum (LF) were exposed using the endoscopic camera. To gain access to the spinal canal, a small incision was created on the LF by using a laminectomy rongeur. For L4-L5 discectomy, a variable drill was used to resect the cranial lamina to enlarge the interlaminar space. For L5-S1 discectomy, the spinal canal was exposed after dissecting the LF. A drill was used in some cases with narrow interlaminar space, such as L5-S1, to create an area easier to work in. Finally, the exposed herniated nucleus pulposus was removed to decompress the nerve root. In one patient with an L5-S1 upward migration disc, an L4-L5 and L5-S1 biportal-IELD was chosen.

\section{Statistical analysis}

GraphPad Prism 5 (La Jolla, CA, USA) was used to assess data. Data are expressed as the mean and range. Multiple $t$ tests were performed to assess functional outcomes. To compare baseline demographic data between IELD and TELD, the chi-square value was calculated. The $t$ test was also used to analyze differences between continuous variables such as the length of stay and operation time. Significance was set at $P<0.05$ for all the tests.

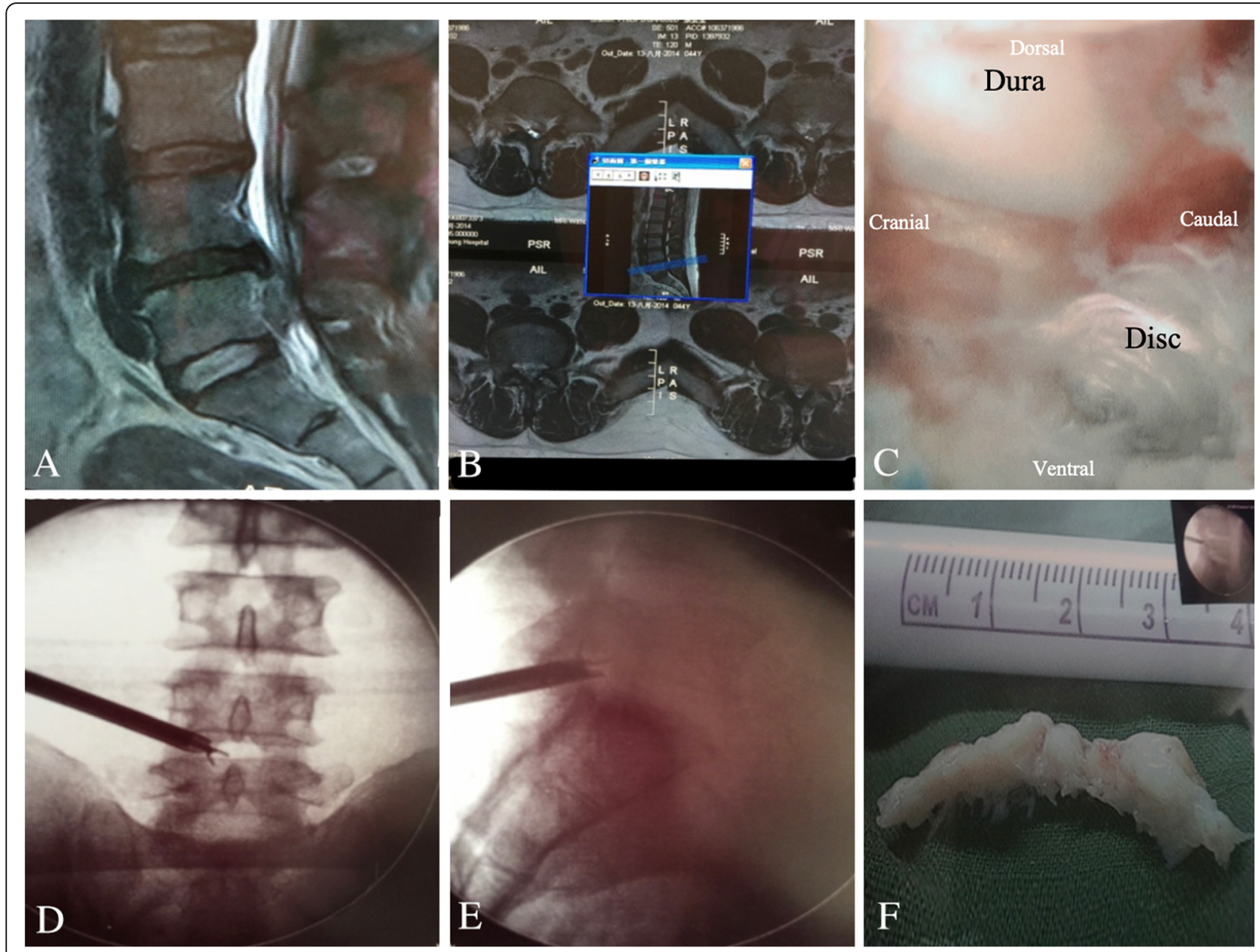

Fig. 6 L4-L5 TELD changed to L5-S1 IELD for L4-L5 high-grade downward migration. a Preoperative MRI lateral view showing high-grade downward migrated disc herniation at the $L 4-L 5$ level. b Preoperative MRI axial views showing disc herniation at the L4-L5 level. c Intraoperative fluoroscopic view of the herniated disc material. d Fluoroscopy anteroposterior view showing forceps near the disc fragment during L4-L5 TELD. e Fluoroscopy lateral view showing the forceps grasping the disc fragment during L5-S1 IELD. f Removed disc fragments 


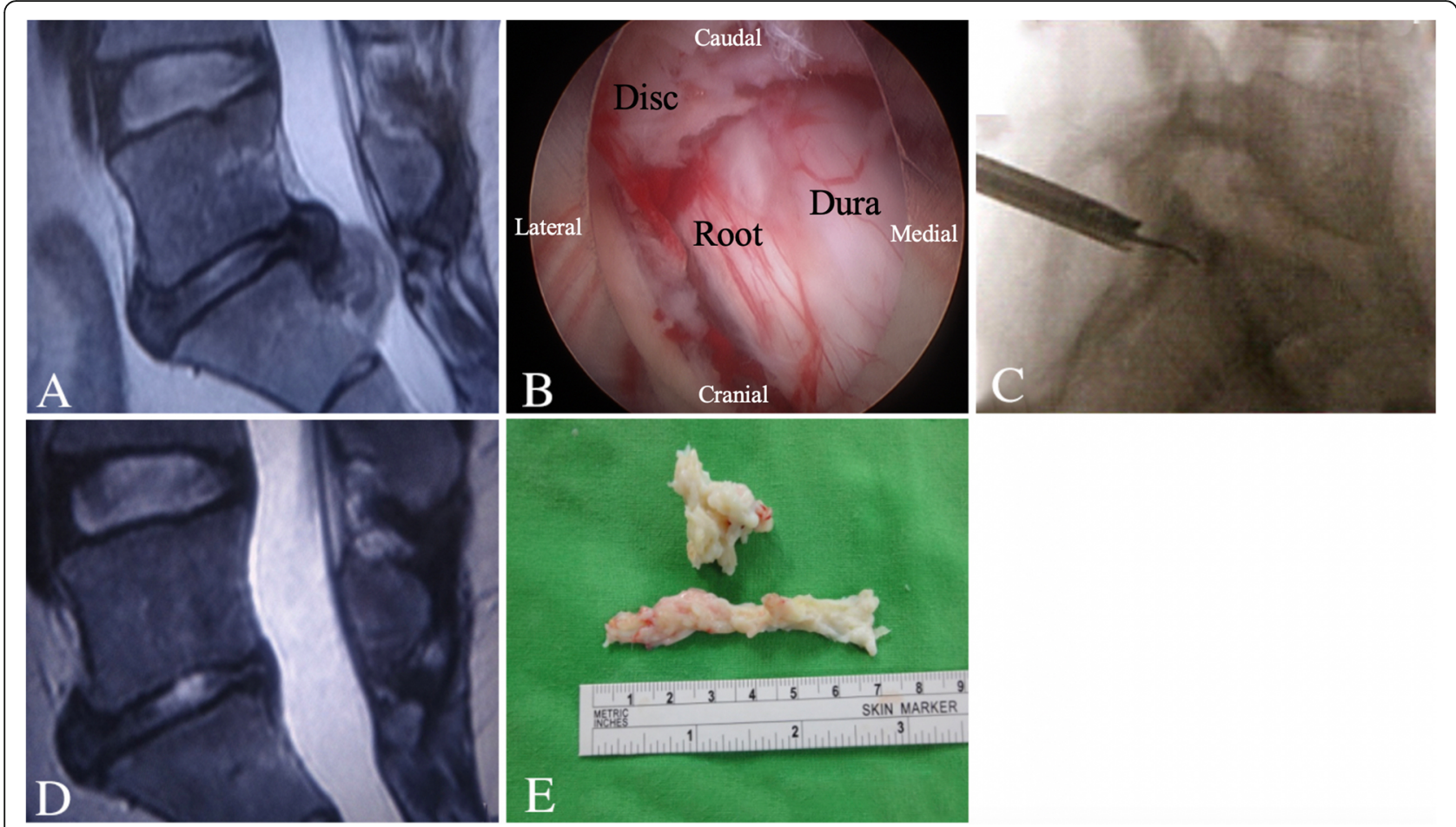

Fig. 7 L5-S1 IELD for L5-S1 high-grade downward migration. a Preoperative MRI lateral view showing L5-S1 high-grade downward migration. b Intraoperative endoscopic view of the migrated disc. c Intraoperative fluoroscopic image of the probe at a high-grade migrated disc. $\mathbf{d}$ Postoperative MRI lateral view of the removed migrated disc. e Removed disc

\section{Results}

\section{Patient demographic and perioperative data}

A total of 68 patients with single-level high-grade migrated discs were enrolled in this study, and 58 patients were followed up for $>5$ years (Table 2). In total, 41 and 17 patients underwent TELD and IELD, respectively. One patient received biportal-IELD for L4-L5 highgrade downward migration (Fig. 5). The operated levels included L1-L2 (1 patient, 1.47\%), L2-L3 (4 patients, $5.88 \%$ ), L3-L4 (6 patients 8.82\%), L4-L5 (36 patients, 67.65\%), and L5-S1 (11 patients16.18\%; Table 2). The average follow-up duration was 6.1 years (range: 5.1-9.2 years). No difference in patient demographics or length of stay was observed between the IELD and TELD groups. However, the TELD group had more patients with zone 1 migration in proximal-level disc herniation $(P=0.032)$ and shorter operation time $(P=0.045)$ than did the IELD group.

\section{Functional outcomes}

Overall visual analog scale (VAS) scores for back pain showed a significant improvement from 6 weeks after the operation (Table 3, Fig. 8). Patients who underwent TELD exhibited faster improvement (3 months postoperatively) than did those who underwent IELD ( 1 year postoperatively); however, no significant difference was observed between the two patient groups. The overall and individual VAS scores for leg pain all significantly improved from 2 weeks after the operation. The Oswestry Disability Index (ODI) significantly improved from 6 weeks postoperatively in both the approaches after the operation.

The percentage of patients with good to excellent results according to the modified MacNab criteria was 91.3\% (53/58 patients). Among the 41 patients who received TELD, the satisfaction rate was $87.8 \%$; five patients exhibited unsatisfactory results. Two patients had a residual disc (1 patient had a repeat TELD the following day, and one patient changed from L4-L5 TELD to L5-S1 IELD during the surgery; Fig. 5). Two patients required an open discectomy due to recurrent disc herniation. One patient (who received IELD) had spinal fusion surgery due to segmental instability after 5 years. The good to excellent result rate was $100 \%$ in the 17 patients who underwent IELD.

\section{Discussion}

\section{Long-term surgical outcomes in high-grade disc migration}

After Kambin introduced the posterolateral percutaneous lumbar disc decompression technique in 1973, the use of minimally invasive surgery has become increasingly common [23]. The advancement of specialized tools, such as flexible probes, lasers, and endoscopes, has 
Table 2 Demographic and Clinical Characteristics of Patients

\begin{tabular}{|c|c|c|c|c|}
\hline & Overall & TELD & IELD & $P$ \\
\hline Overall & 58 & 41 & 17 & \\
\hline Age (years) & $56.3(18-78)$ & $56.7(18-72)$ & $55.2(18-78)$ & 0.462 \\
\hline Sex & $38 \mathrm{~F} 20 \mathrm{M}$ & $27 \mathrm{~F} 14 \mathrm{M}$ & $11 \mathrm{~F} 6 \mathrm{M}$ & 0.332 \\
\hline ASA & & & & 0.175 \\
\hline 1 & 32 & 24 & 8 & \\
\hline 2 & 15 & 10 & 5 & \\
\hline 3 & 11 & 6 & 5 & \\
\hline Zone 1 & & & & 0.032 \\
\hline L1-L2 & 1 & 1 & 0 & \\
\hline L2-L3 & 4 & 4 & 0 & \\
\hline L3-L4 & 4 & 4 & 0 & \\
\hline L4-L5 & 10 & 8 & 2 & \\
\hline L5-S1 & 7 & 0 & 7 & \\
\hline Zone 4 & & & & 0.511 \\
\hline L1-L2 & 0 & 0 & 0 & \\
\hline L2-L3 & 0 & 0 & 0 & \\
\hline L3-L4 & 2 & 2 & 0 & \\
\hline L4-L5 & 26 & 21 & 5 & \\
\hline L5-S1 & 4 & 1 & 3 & \\
\hline Operation duration (minutes) & $55.7(28-128)$ & $50.6(28-85)$ & $65.5(45-128)$ & 0.045 \\
\hline Length of stay (days) & $5.2(3-7)$ & $4.6(3-6)$ & $5.8(3-7)$ & 0.082 \\
\hline Follow-up (years) & $6.1(5.1-9.2)$ & $6.3(5.1-7.8)$ & $5.7(5.5-9.2)$ & 0.617 \\
\hline
\end{tabular}

ASA American Society of Anesthesiologists classification, IELD Interlaminar endoscopic lumbar discectomy, TELD Transforaminal endoscopic lumbar discectomy

made FELD highly popular [24]. FELD has been limited to the management of low-grade migrated lumbar disc herniation and has not been used for highly migrated discs, which pose technical challenges to spine surgeons [17]. Lee et al. reported that patients with high-grade migration had a significantly higher incidence of failure (21.1\%) than did those with low-grade migration [22]. Recently, various techniques have been developed to treat high-grade migrated discs, and these techniques have shown promising results (Table 2). In our study, we found that TELD and IELD both resulted in satisfactory long-term functional outcomes for high-grade migrated disc herniation.

\section{TELD for migrated discs}

TELD and open discectomy have exhibited similar results in the management of soft high-grade disc migration; moreover, TELD is a safe and effective procedure especially from L1 to L5 [11]. The migratory patterns of the disc fragment are usually restricted by the attachment of the posterior longitudinal ligament, peridural membrane, and midline septum [25]. Thus, to enter the foramen, they remain on the lateral side of the midline [4]. Osman et al. showed that without sacrificing stability, transforaminal decompression can create a considerably larger intervertebral foraminal space compared with posterior decompression ( $45.5 \%$ vs. $34.2 \%$ increase) [23]. Furthermore, upward-migrated herniations are common in older patients with associated comorbidities such as diabetes and hypertension, making them ineligible to receive general anesthesia and open surgery [26, 27]. Positioning the patient to achieve hip flexion and low lordosis enlarges the foramen; consequently, the space is sufficiently large for performing TELD without requiring foraminoplasty. However, for zone 1 and zone 4 migration, Kim et al. reported a transforaminal suprapedicular approach with a flexible semirigid curved probe. Curved forceps are extremely useful for the complete removal of very-high-grade disc migration, allowing the surgeon to reach distant sites and remove disc fragments without further bone resection and release soft tissue adhesions [4].

Reamers and endoscopic drills, endoscopic osteotomes, and trepans can help remove the barrier of the pedicle to the disc for highly migrated discs. When performing this step, the surgeon should be extremely careful to prevent neural damage or the significant removal of bony structures leading to lumbar instability. Thus, 
Table 3 Satisfaction in patients receiving interlaminar and translaminar endoscopic lumbar discectomy

\begin{tabular}{|c|c|c|c|c|c|c|c|}
\hline \multirow[b]{2}{*}{ VAS for back } & \multicolumn{2}{|c|}{ Overall $(N=58)$} & \multicolumn{2}{|c|}{ IELD $(N=17)$} & \multicolumn{2}{|c|}{ TELD $(N=41)$} & \multirow[b]{2}{*}{$P$ value } \\
\hline & Mean & SD & Mean & SD & Mean & SD & \\
\hline Preop & 2.22 & 1.57 & 2.34 & 1.76 & 2.29 & 1.76 & 0.92 \\
\hline Postop 2 weeks & 2.30 & 1.68 & 2.30 & 1.76 & 2.45 & 1.69 & 0.76 \\
\hline Postop 6 weeks & 1.44 & 1.60 & 1.50 & 1.68 & 1.55 & 1.72 & 0.92 \\
\hline Postop 3 months & 1.40 & 1.20 & 1.39 & 1.32 & 1.51 & 1.31 & 0.75 \\
\hline Postop 6 months & 1.20 & 1.10 & 1.35 & 1.03 & 1.44 & 1.12 & 0.78 \\
\hline Postop 1 year & 1.03 & 0.84 & 1.07 & 0.82 & 1.05 & 0.77 & 0.93 \\
\hline Postop 2 years & 0.46 & 0.80 & 0.45 & 0.85 & 0.48 & 0.85 & 0.90 \\
\hline Postop 5 years & 0.45 & 0.60 & 0.44 & 0.63 & 0.44 & 0.63 & $>0.99$ \\
\hline VAS for leg & Mean & SD & Mean & SD & Mean & SD & $P$ value \\
\hline Preop & 6.21 & 1.64 & 2.34 & 1.70 & 2.29 & 1.66 & 0.92 \\
\hline Postop 2 weeks & 2.33 & 1.85 & 2.30 & 1.82 & 2.45 & 1.87 & 0.76 \\
\hline Postop 6 weeks & 1.52 & 1.30 & 1.50 & 1.31 & 1.55 & 1.31 & 0.92 \\
\hline Postop 3 months & 1.38 & 0.72 & 1.39 & 0.73 & 1.51 & 0.73 & 0.75 \\
\hline Postop 6 months & 0.72 & 0.87 & 1.35 & 0.90 & 1.44 & 0.82 & 0.78 \\
\hline Postop 1 year & 0.64 & 0.72 & 1.07 & 0.73 & 1.05 & 0.73 & 0.93 \\
\hline Postop 2 years & 0.57 & 0.73 & 0.45 & 0.74 & 0.48 & 0.71 & 0.90 \\
\hline Postop 5 years & 0.43 & 0.50 & 0.44 & 0.50 & 0.44 & 0.50 & $>0.99$ \\
\hline ODI & Mean & SD & Mean & SD & Mean & SD & $P$ value \\
\hline Preop & 46.73 & 13.07 & 46.24 & 13.20 & 46.67 & 13.36 & 0.91 \\
\hline Postop 2 weeks & 45.00 & 12.12 & 45.18 & 12.25 & 45.76 & 11.83 & 0.87 \\
\hline Postop 6 weeks & 33.51 & 14.71 & 33.06 & 14.88 & 33.73 & 14.90 & 0.88 \\
\hline Postop 3 months & 19.63 & 10.38 & 18.76 & 9.81 & 19.46 & 10.27 & 0.81 \\
\hline Postop 6 months & 20.40 & 12.57 & 20.77 & 12.84 & 20.66 & 12.90 & 0.98 \\
\hline Postop 1 year & 11.18 & 10.14 & 10.84 & 10.38 & 11.11 & 10.41 & 0.93 \\
\hline Postop 2 years & 8.72 & 4.41 & 8.83 & 4.44 & 8.86 & 4.41 & 0.98 \\
\hline Postop 5 years & 6.60 & 3.53 & 6.30 & 3.42 & 6.46 & 3.49 & 0.87 \\
\hline \multicolumn{8}{|l|}{ Modified MacNab } \\
\hline Excellent & 36 & & 11 & & 25 & & 0.49 \\
\hline Good & 17 & & 6 & & 11 & & \\
\hline Fair & 4 & & 0 & & 4 & & \\
\hline Poor & 1 & & 0 & & 1 & & \\
\hline
\end{tabular}

surgeons are recommended to use endoscopic drills or endoscopic osteotomes to increase precision.

In this study, patients who received TELD had higher VAS and ODI scores than did those who received IELD, probably because TELD caused less damage than IELD through the facet joint during the exploration of the migrated disc. Furthermore, TELD has a shorter operating time than IELD does because TELD requires less bone work and soft tissue management.

The zone with highest number of failed cases of TELD in the present study was in zone 1 . The migrated disc at the ipsilateral side was usually blocked by the pedicle unless contralateral TELD was used [13]. The surgeon may be unable to grasp the fragment due to the nonflexible instrument being unable to make an acute turn to reach the area. The contralateral approach enables the surgeon to reach the fragment directly because the angle between the instrument and the migrated fragment is straight. If a bone drill or trephine is available, the use of the translaminar approach [17], transpedicular approach $[15,28]$, or keyhole procedure for directly targeting the migrated disc can result in a satisfactory outcome. Foraminoplasty is needed to access high-grade migrated disc herniations for multiple reasons. First, lumbar herniation occurs most frequently at lower levels. The diameter of the intervertebral foramen decreases in the lumbar area, 


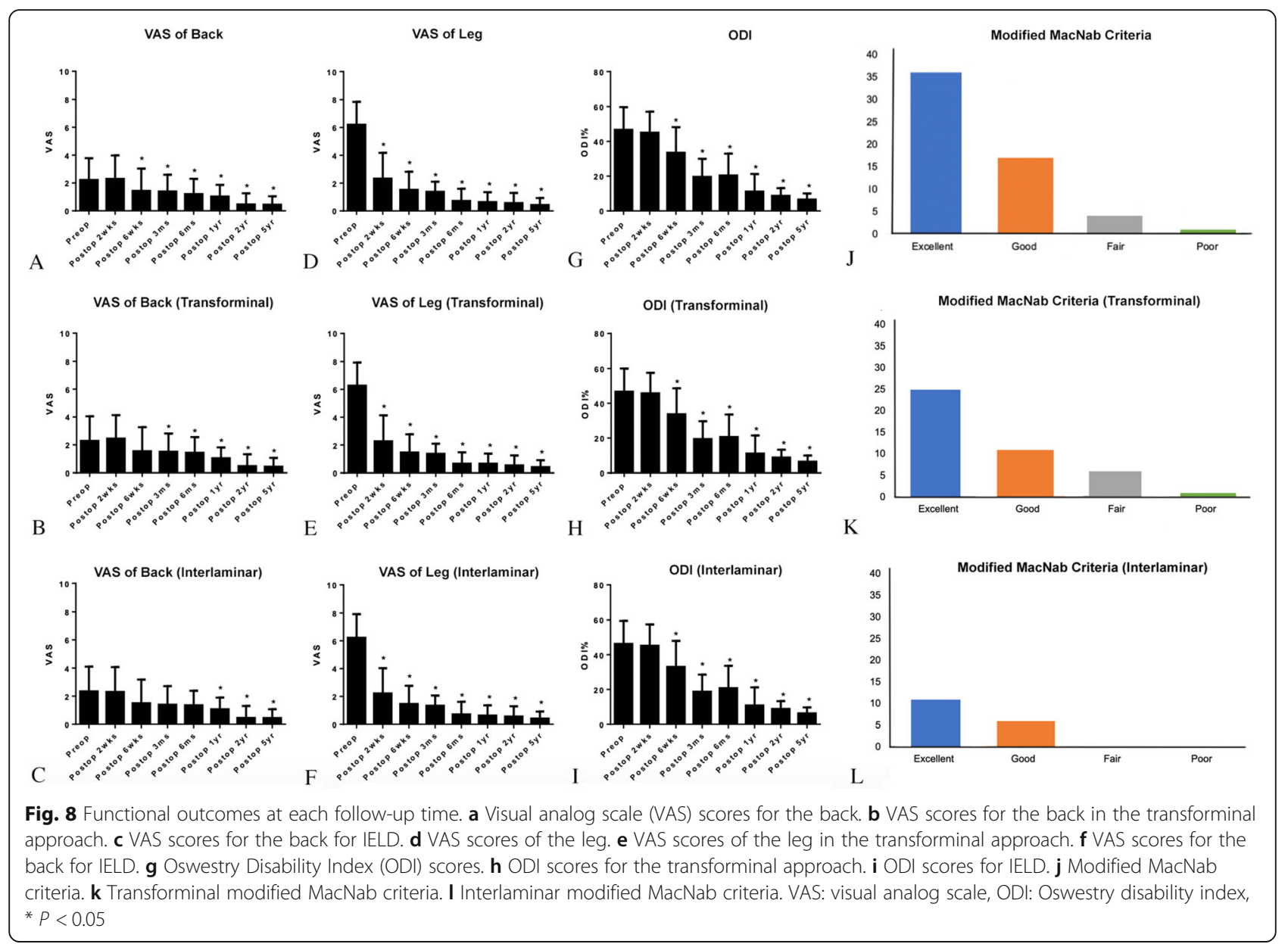

from cranial to caudal. Narrowing may result from degenerative changes due to the hypertrophy and the overriding of facets and the thickening of the LF. For adequate decompression, the anterior epidural space must be reached under direct visual control. Enlarging the foramen by undercutting the superior articular facet can facilitate reaching the epidural space and ensure the adequate exposure or complete removal of the fragment [29].

\section{IELD}

In this study, IELD was more effective than TELD for L4-L5 high-grade downward and L5-S1 high-grade upward and downward migration discs, except in failed cases. Axillary herniated discs can be easily removed using IELD. The S1 nerve root exit at the L5-S1 level disc space is unique. The angle between the S1 root and thecal sac allows access to the axillary portion of the S1 nerve root. An increase in the angle between the root and thecal sac in axillary disc herniation increases the working space for the cannula without damaging the root. IELD can directly access the axillary herniated disc and remove the disc fragment with minimal manipulation of the neural structure. However, with the use of TELD, incomplete decompression or a remnant disc is possible. The posterior longitudinal ligament must be cut to retrieve the dorsally migrated disc fragment [19].

As shown in Table 4, after gaining the in-depth knowledge of surgical anatomy and ensuring strict adherence to technical guidelines, endoscopic surgery does not yield poor outcomes when performed for managing high-grade disc migration. Using an accurate approach for the proper indication remains the most crucial point. Doctors must gain in-depth knowledge of surgical anatomy and ensure strict adherence to technical guidelines; familiarity with IELD and TELD is particularly important. TELD is preferred for shoulder-type disc herniation, centrally located disc herniation, and recurrent disc herniation. IELD is preferred for axillary-type disc herniation and migrated discs, particularly high-grade disc migration and disc herniation.

A limitation of this study is the retrospective nature of data collection. However, the prospective spine registry effectively collected postoperative function scores, which reduced missing data. In addition, selection bias due to 


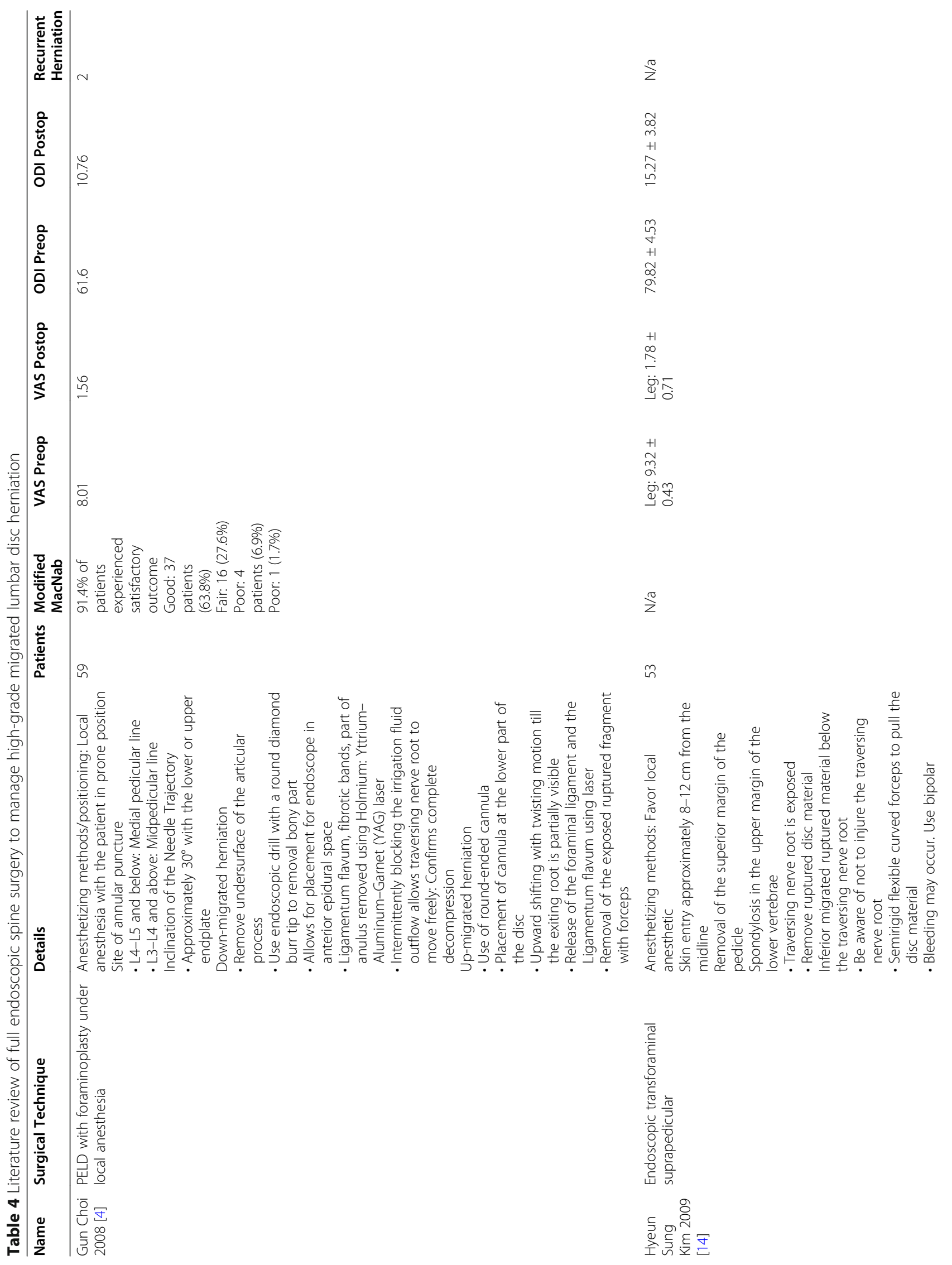




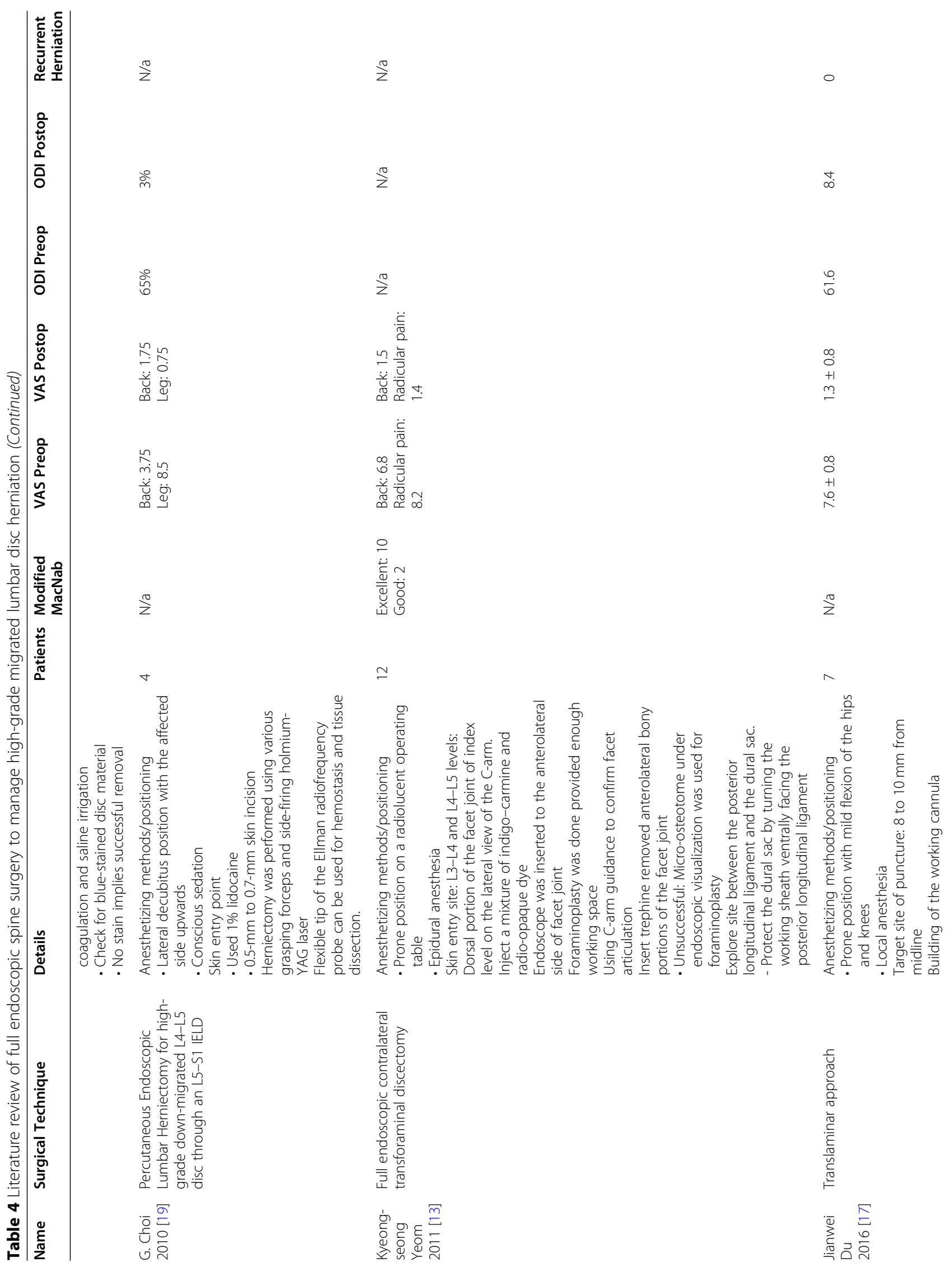




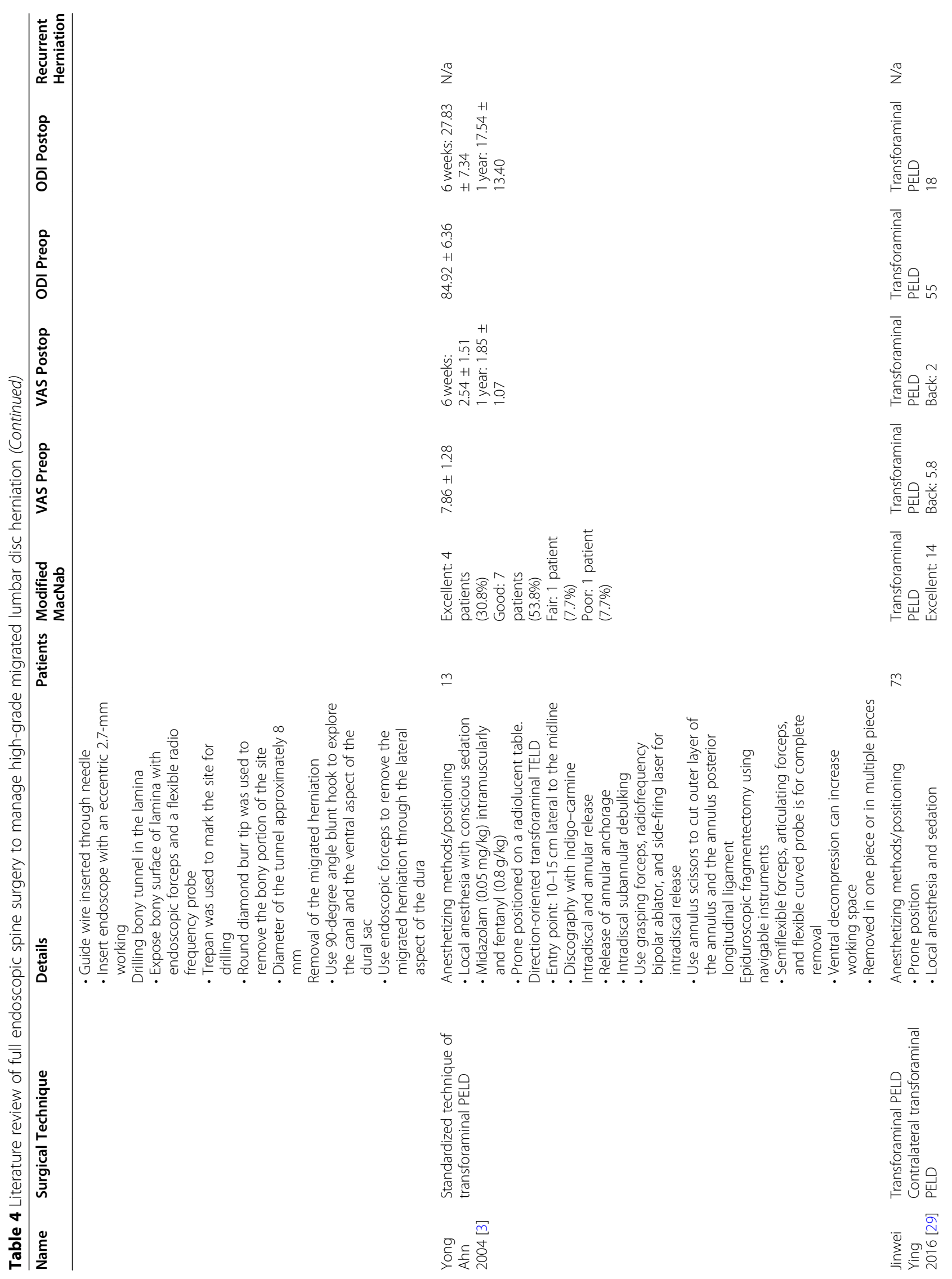




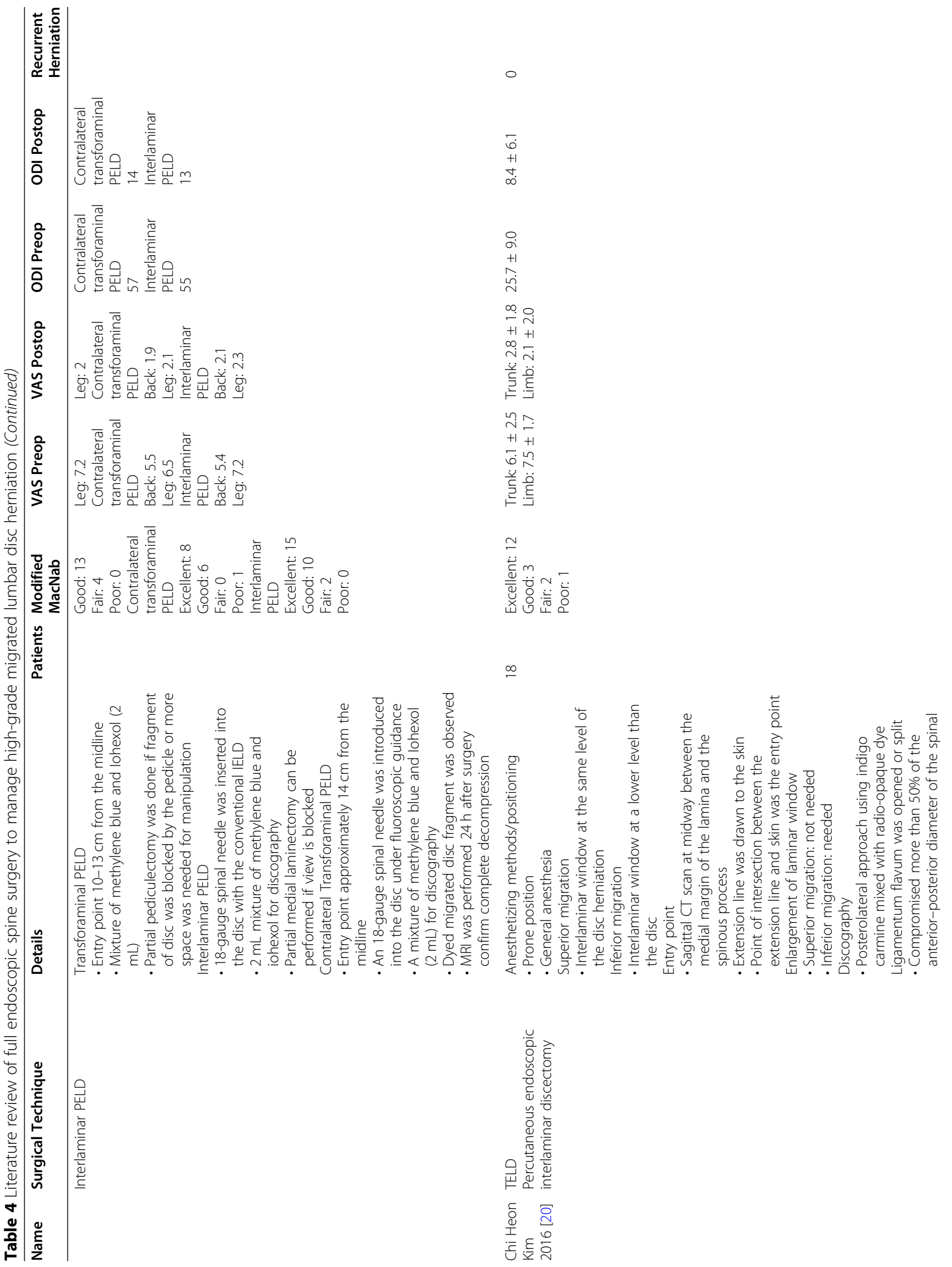




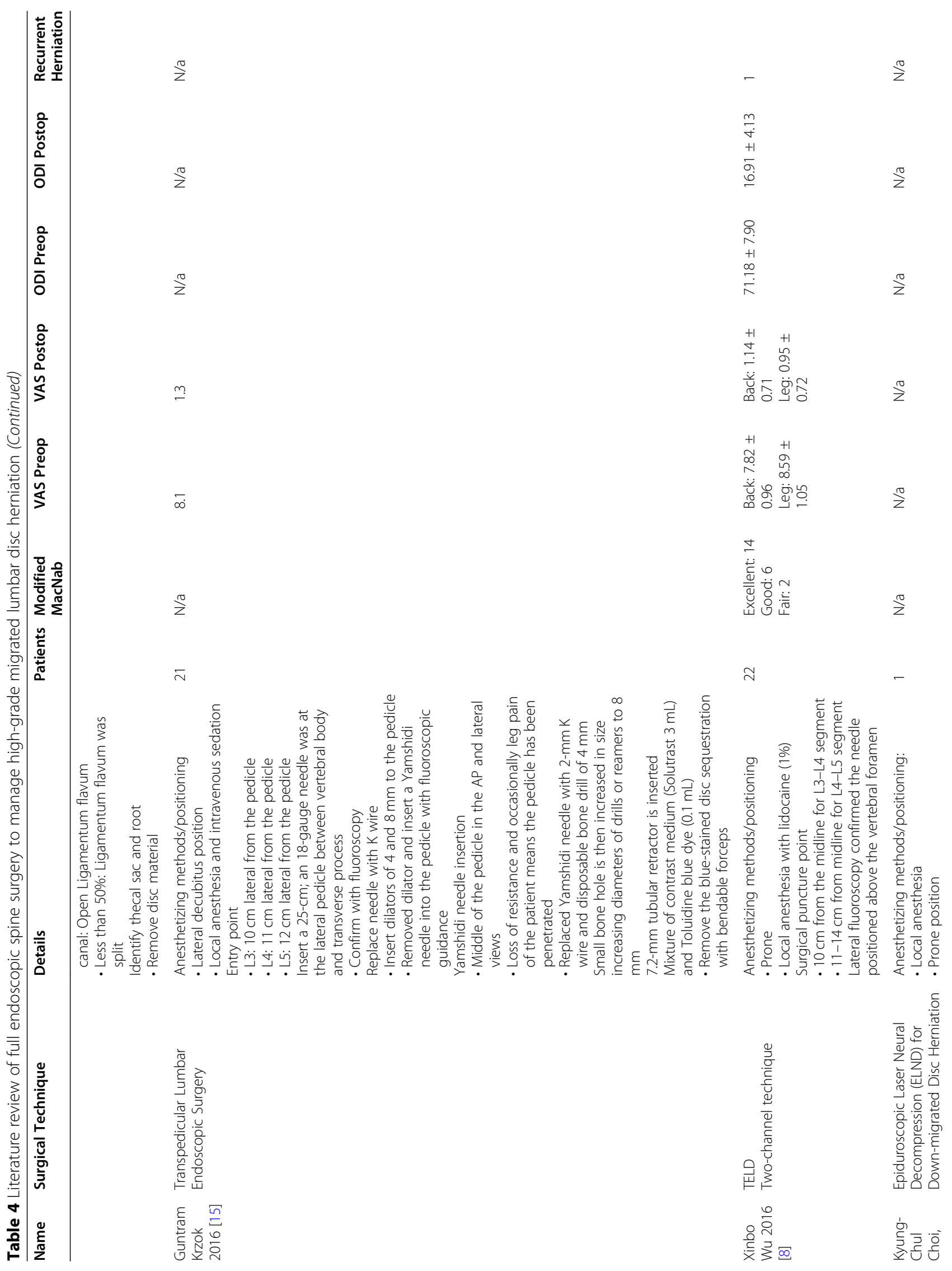




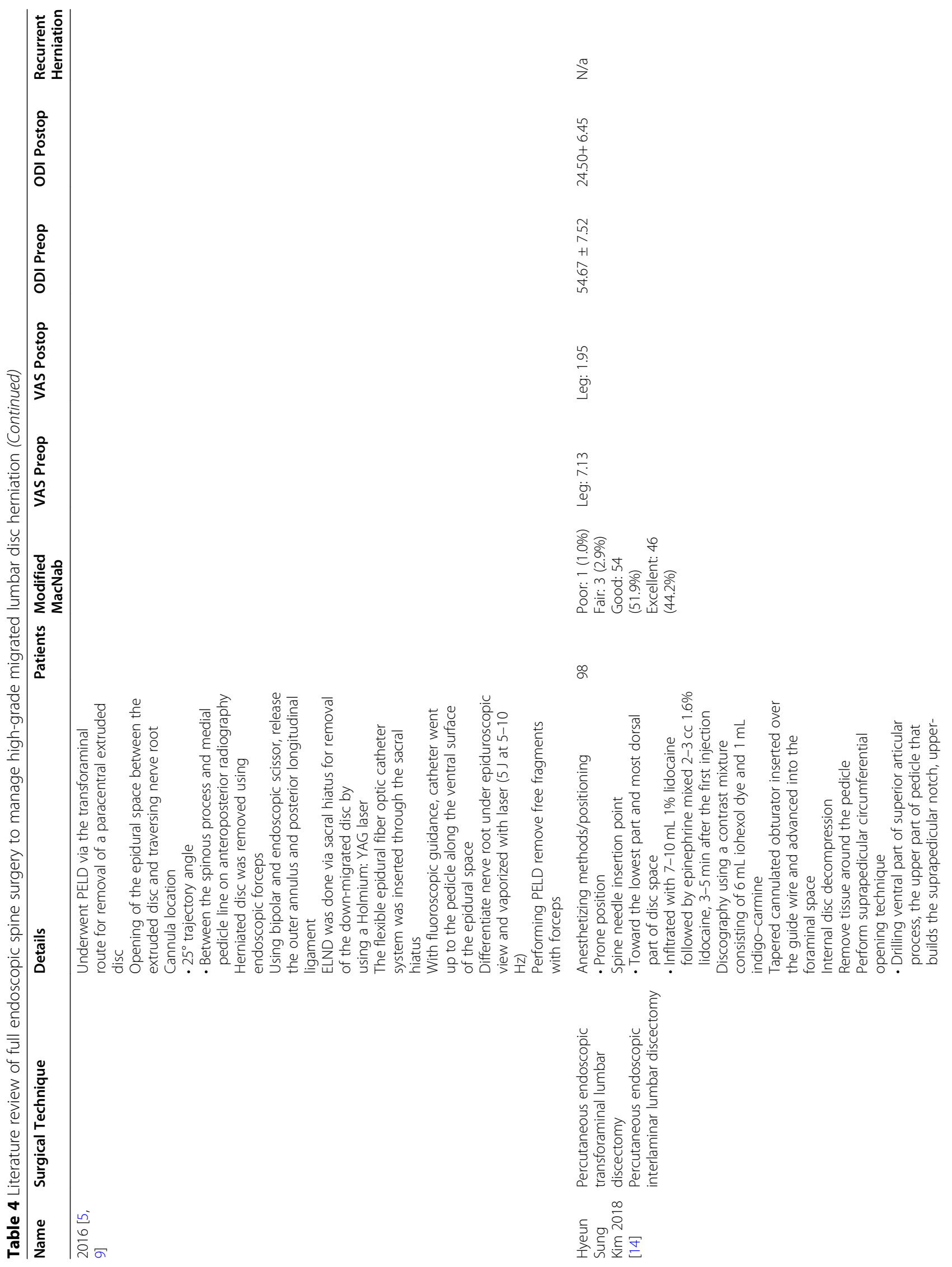




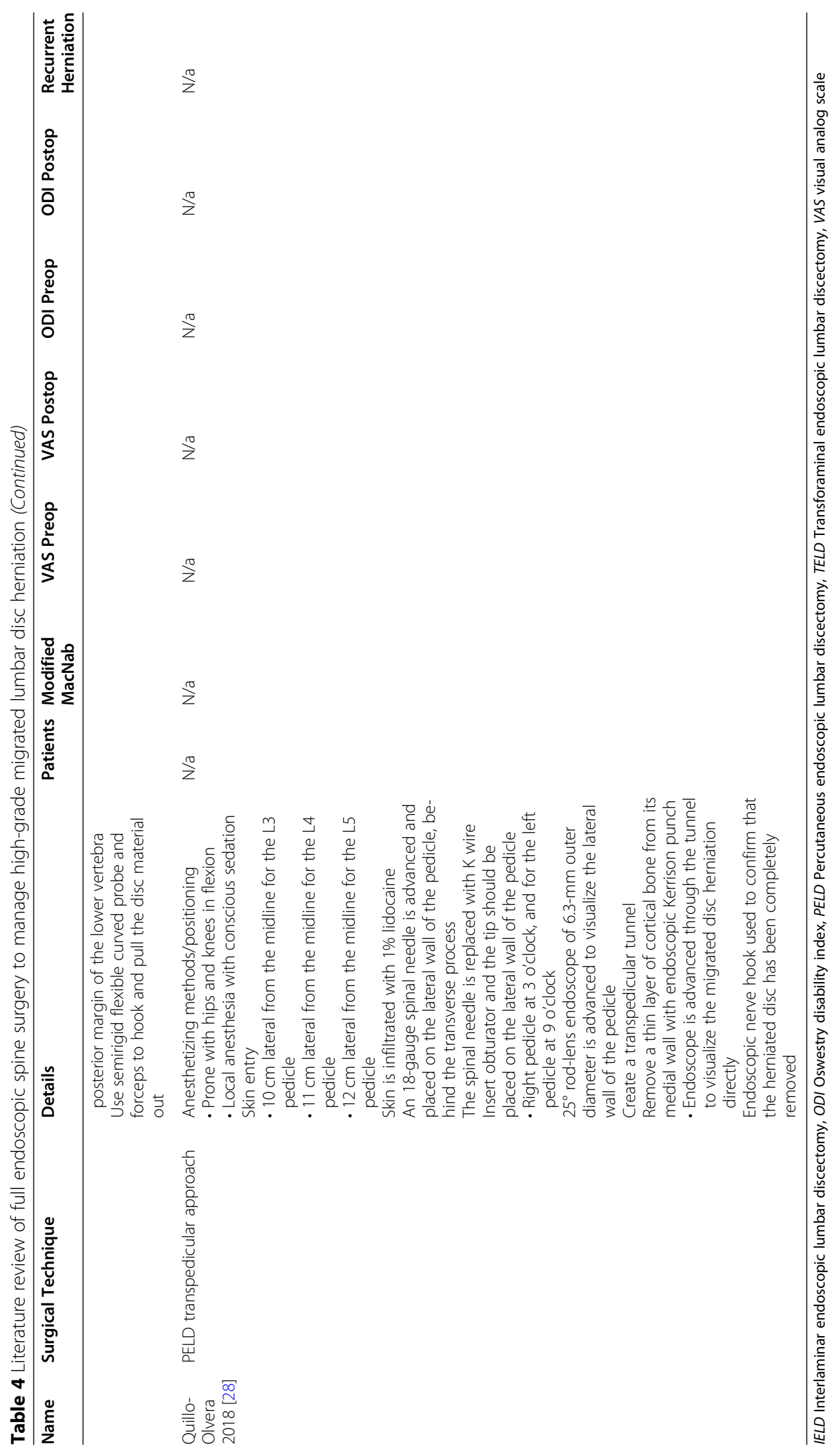


loss to follow-up remains a concern in this study. However, we had a follow-up rate of $>80 \%$ for patients with high-grade migrated discs, which reduced the bias. Furthermore, this study is limited by its small sample size, and the power of the study in comparing TELD and IELD was not evaluated. Additional studies comparing TELD and IELD for high-grade disc migration are needed. Another limitation of this study is long patient hospitalization due to affordable health care expenses, which may not be comparable to other studies.

\section{Conclusion}

FELD has a high success rate for the management of high-grade disc migration and disc herniation. TELD is effective and safe for patients with high-grade disc migration from L1 to L5. In patients with L4-L5 and L5S1 high-grade upward and downward disc migration, IELD is a favorable option providing high patient satisfaction.

\section{Abbreviations}

FELD: Full-endoscopic lumbar discectomy; TELD: Transforaminal endoscopic lumbar discectomy; IELD: Interlaminar endoscopic lumbar discectomy; $\mathrm{CT}$ : Computed tomography; MRI: Magnetic resonance imaging: LF: Ligamentum flavum; VAS: Visual analog scale; ODI: Oswestry Disability Index

\section{Acknowledgments}

The authors would like to acknowledge the assistance of Ms. Yu-Yin Wei from the Office of Research and Development, Taipei Medical University and Ms. Monica Wang for illustrations in this manuscript. We appreciate the support from Taipei Medical University (TMU109-AE1-B01). This manuscript was edited by Wallace Academic Editing.

\section{Authors' contributions}

M.H.W and S.K.H were responsible for designing and setting up the study. C.W and M.H.W prepared the manuscript draft. All authors contributed to initial discussions regarding data extraction and analyses, the interpretation of study findings, and the development of the manuscript. All authors have critically reviewed and approved the final version of the submitted manuscript.

\section{Funding}

The study received funding support from Taipei Medical University (TMU109AE1-B01).

\section{Availability of data and materials}

The data supporting our findings can be found in the article.

\section{Ethics approval and consent to participate}

This study was approved by Taipei Medical University- Joint Institution Review Board (TMU-JIRB No.: N201903139). The registry data, chart, and image reviews were approved with the waiver of informed consent.

\section{Consent for publication}

Not applicable.

\section{Competing interests}

The authors report no conflict of interest concerning the materials or methods used in this study or the findings stated in this manuscript.

\section{Author details}

${ }^{1}$ College of Medicine, Taipei Medical University, Taipei, Taiwan. ${ }^{2}$ Department of Orthopaedics, School of Medicine, College of Medicine, Taipei Medical University, Taipei, Taiwan. ${ }^{3}$ Department of Orthopedics, Taipei Medical
University Hospital, R.O.C, No. 252,Wuxing St., Xinyi Dist., Taipei 11031 Taiwan. ${ }^{4}$ Department of Orthopedics, Tungs' Taichung MetroHarbor Hospital, No.699, Sec. 8, Taiwan Blvd., Taichung City 435, Taiwan.

Received: 10 July 2020 Accepted: 16 December 2020

Published online: 09 January 2021

\section{References}

1. Hijikata S. Percutaneous nucleotomy. A new concept technique and 12 years' experience. Clin Orthop Relat Res. 1989;238:9-23.

2. Gadjradj PS, van Tulder MW, Dirven CM, Peul WC, Harhangi BS. Clinical outcomes after percutaneous transforaminal endoscopic discectomy for lumbar disc herniation: a prospective case series. Neurosurg Focus. 2016; 40(2):E3.

3. Ahn Y, Lee SH, Park WM, Lee HY, Shin SW, Kang HY. Percutaneous endoscopic lumbar discectomy for recurrent disc herniation: surgical technique, outcome, and prognostic factors of 43 consecutive cases. Spine (Phila Pa 1976). 2004;29(16):E326-32.

4. Choi G, Lee SH, Lokhande P, Kong BJ, Shim CS, Jung B, Kim JS. Percutaneous endoscopic approach for highly migrated intracanal disc herniations by foraminoplastic technique using rigid working channel endoscope. Spine (Phila Pa 1976). 2008;33(15):E508-15.

5. Choi KC, Lee DC, Shim HK, Shin SH, Park CK. A strategy of percutaneous endoscopic lumbar discectomy for migrated disc herniation. World Neurosurg. 2017:99:259-66.

6. Ahn Y, Jeong TS, Lim T, Jeon JY. Grading system for migrated lumbar disc herniation on sagittal magnetic resonance imaging: an agreement study. Neuroradiology. 2018;60(1):101-7.

7. Lewandrowski K-U, Lee S-H, Iprenburg M. Endoscopic spinal surgery; 2013.

8. Wu X, Fan G, Guan X, Zhu Y, Huang L, He S, Gu X. Percutaneous endoscopic lumbar discectomy for far-migrated disc herniation through two working channels. Pain Physician. 2016;19(4):E675-80.

9. Choi KC, Shim HK, Park CJ, Lee DC, Park CK. Usefulness of percutaneous endoscopic lumbar foraminoplasty for lumbar disc herniation. World Neurosurg. 2017:106:484-92

10. Hofstetter CP, Ahn Y, Choi G, Gibson JNA, Ruetten S, Zhou Y, Li ZZ, Siepe $\mathrm{CJ}$, Wagner $\mathrm{R}$, Lee $\mathrm{JH}$, et al. AOSpine consensus paper on nomenclature for working-channel endoscopic spinal procedures. Global Spine J. 2020;10(2 Suppl):111S-21S.

11. Lewandrowski KU, Ransom NA. Five-year clinical outcomes with endoscopic transforaminal outside-in foraminoplasty techniques for symptomatic degenerative conditions of the lumbar spine. J Spine Surg. 2020;6(Suppl 1): S54-65.

12. Hu QF, Pan H, Fang YY, Jia GY. Percutaneous endoscopic lumbar discectomy for high-grade down-migrated disc using a trans-facet process and pedicle-complex approach: a technical case series. Eur Spine J. 2018; 27(Suppl 3):393-402.

13. Yeom KS, Choi YS. Full endoscopic contralateral transforaminal discectomy for distally migrated lumbar disc herniation. J Orthop Sci. 2011;16(3):263-9.

14. Kim HS, Ju Cl, Kim SW, Kim JG. Endoscopic transforaminal suprapedicular approach in high grade inferior migrated lumbar disc herniation. J Korean Neurosurg Soc. 2009:45(2):67-73.

15. Krzok G, Telfeian AE, Wagner R, Iprenburg M. Transpedicular lumbar endoscopic surgery for highly migrated disk extrusions: preliminary series and surgical technique. World Neurosurg. 2016;95:299-303.

16. Kim JS, Choi G, Lee SH. Percutaneous endoscopic lumbar discectomy via contralateral approach: a technical case report. Spine (Phila Pa 1976). 2011 36(17):E1173-8

17. Du J, Tang $X$, Jing $X$, Li N, Wang $Y$, Zhang $X$. Outcomes of percutaneous endoscopic lumbar discectomy via a translaminar approach, especially for soft, highly down-migrated lumbar disc herniation. Int Orthop. 2016;40(6): 1247-52.

18. Xin Z, Liao W, Ao J, Qin J, Chen F, Ye Z, Cai Y. A modified translaminar osseous channel-assisted percutaneous endoscopic lumbar discectomy for highly migrated and sequestrated disc herniations of the upper lumbar: clinical outcomes, surgical indications, and technical considerations. Biomed Res Int. 2017;2017:3069575

19. Choi G, Prada N, Modi HN, Vasavada NB, Kim JS, Lee SH. Percutaneous endoscopic lumbar herniectomy for high-grade down-migrated L4-L5 disc through an L5-S1 interlaminar approach: a technical note. Minim Invasive Neurosurg. 2010;53(3):147-52. 
20. Kim CH, Chung CK, Woo JW. Surgical outcome of percutaneous endoscopic interlaminar lumbar discectomy for highly migrated disk herniation. Clin Spine Surg. 2016;29(5):E259-66.

21. Inomata Y, Oshima Y, Inoue H, Takano Y, Inanami H, Koga H. Percutaneous endoscopic lumbar discectomy via adjacent interlaminar space for highly down-migrated lumbar disc herniation: a technical report. J Spine Surg. 2018;4(2):483-9.

22. Lee S, Kim SK, Lee SH, Kim WJ, Choi WC, Choi G, Shin SW. Percutaneous endoscopic lumbar discectomy for migrated disc herniation: classification of disc migration and surgical approaches. Eur Spine J. 2007;16(3):431-7.

23. Kambin P, Gellman H. Percutaneous lateral discectomy of the lumbar spine: a preliminary report. Clin Orthop Relat Res. 1983;174:127-32.

24. Yeung A, Lewandrowski KU. Five-year clinical outcomes with endoscopic transforaminal foraminoplasty for symptomatic degenerative conditions of the lumbar spine: a comparative study of inside-out versus outside-in techniques. J Spine Surg. 2020;6(Suppl 1):S66-83.

25. Schellinger D, Manz HJ, Vidic B, Patronas NJ, Deveikis JP, Muraki AS, Abdullah DC. Disk fragment migration. Radiology. 1990;175(3):831-6.

26. Osman SG, Nibu K, Panjabi MM, Marsolais EB, Chaudhary R. Transforaminal and posterior decompressions of the lumbar spine. A comparative study of stability and intervertebral foramen area. Spine (Phila Pa 1976). 1997;22(15): 1690-5.

27. Akagi S, Saito T, Kato I, Sasai K, Ogawa R. Clinical and pathologic characteristics of lumbar disk herniation in the elderly. Orthopedics. 2000; 23(5):445-8.

28. Quillo-Olvera J, Akbary K, Kim JS. Percutaneous endoscopic transpedicular approach for high-grade down-migrated lumbar disc herniations. Acta Neurochir. 2018;160(8):1603-7.

29. Ying J, Huang K, Zhu M, Zhou B, Wang Y, Chen B, Teng H. The effect and feasibility study of transforaminal percutaneous endoscopic lumbar discectomy via superior border of inferior pedicle approach for downmigrated intracanal disc herniations. Medicine (Baltimore). 2016;95(8):e2899.

\section{Publisher's Note}

Springer Nature remains neutral with regard to jurisdictional claims in published maps and institutional affiliations.

Ready to submit your research? Choose BMC and benefit from:

- fast, convenient online submission

- thorough peer review by experienced researchers in your field

- rapid publication on acceptance

- support for research data, including large and complex data types

- gold Open Access which fosters wider collaboration and increased citations

- maximum visibility for your research: over $100 \mathrm{M}$ website views per year

At $\mathrm{BMC}$, research is always in progress.

Learn more biomedcentral.com/submissions 